\title{
Regulatory Need: Harmonized PIC/S GMP, Its Overview and Comparison with WHO GMP
}

\section{Charmy Kothari* and Rushvi Patel}

Department of Pharmaceutical Analysis, Institute of Pharmacy, Nirma University, Ahmedabad, India

\begin{abstract}
Currently, it is necessary to increase harmonization efforts in setting regulatory requirements, inspecting and evaluating GMP compliance, licensing manufacturing sites, recalling defective batches and increasing the exchange of information due to the increased globalization regulatory authorities. PIC/S offers attractive and stable platform to respond such challenges of the globalization. PIC/S actively encourage networking by organizing a "PIC/S GMP Forum" which allow non-member authorities, professional and other organizations to meet informally with the PIC/S Committee. PIC/s has established harmonized guide on GMP requirements for inspectorate and industry. There is the complementarity co-operation between the PIC/S and other organization. PIC/S participating authority co-operates actively and avoids the duplication of his member's efforts. Till date, 46 countries are the member of the PIC/S and 10 countries are under Accession and Pre-Accession Procedure. PIC/S provide the sharing of the inspection report between the member authorities which allow them to prove their GMP facility equivalent to PIC/S standard and resulting into the reduction of the number of inspection and duplication of the inspection. Joining to PIC/S will endorse the Indian pharmaceutical companies to be reliable exporters of quality medicines globally. While for Indian Pharma Companies to meet the PIC/S requirement would not be like cakewalk especially for MSME Pharma segment that needs to upgrade their GMP facilities. Thus it will be challenging for stake holders to join PIC/S but simultaneously there will be bigger hurdles of not joining the PIC/S. While approaching to PIC/S, a careful examination is needed by India during export as maintaining high quality standards for export markets. PIC/S is bringing a great revolution in the GMP standards to establish the high quality in the drug product and thus INDIA should become the member of PIC/S to raise its GMP standards as it is recognized as 'power house' of pharmaceutical manufacturing.
\end{abstract}

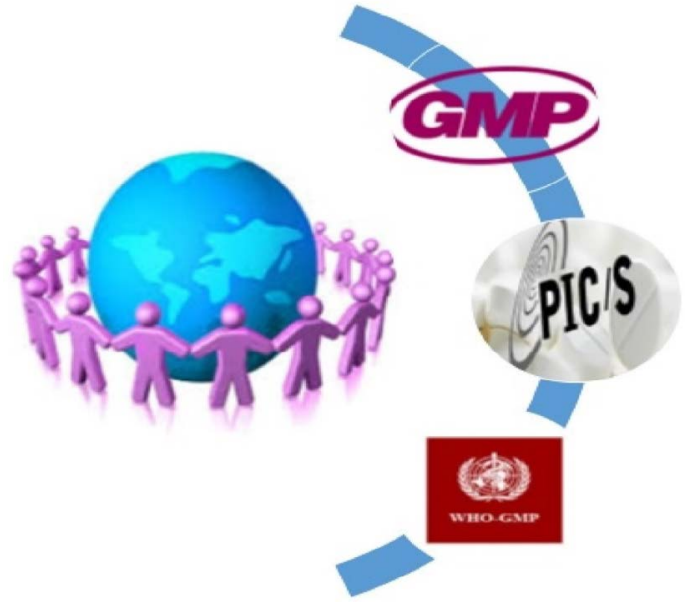

Keywords: PIC/s; WHO GMP; PIC/s GMP; Harmonized GMP; Regulatory need

\section{Abbreviations}

WHO: World Health Organization; EMEA: European Medicines Evaluation Agency; EU: European Union; EFTA: European Free Trade Association; TGA: Therapeutic Goods Administration; FDA: Food and Drug Administration; PIC: Pharmaceutical Inspection Convention; PIC/S: Pharmaceutical Inspection Cooperation/ Scheme; GMP: Good Manufacturing Practice; MSME: Ministry of Micro Small and Medium Enterprise; IMID: International Medicinal Inspectorate Database; CEP: Certificate of Suitability; API: Active Pharmaceutical Ingredients

\section{Introduction}

Pharmaceutical Inspection Co-operation Scheme was established on the $2^{\text {nd }}$ November 1950 as it is extension of the Pharmaceutical Inspection Convention which was founded in 1970. As PIC was founded by the European Free Trade Association (EFTA) under the title of "The Convention for the Mutual Recognition of Inspections in Respect of the Manufacture of Pharmaceutical Products", with aim of removal of non-tariff barrier in trade of pharmaceutical in Europe through mutual recognition of inspection report and certification

*Corresponding author: Charmy Kothari, Assistant Professor, Department of Pharmaceutical Analysis, Institute of Pharmacy, Nirma University, Ahmedabad, India, Tel: +919898617612; E-mail: charmyshah@gmail.com

Received August 11, 2015; Accepted August 25, 2015; Published August 28, 2015

Citation: Kothari C, Patel R (2015) Regulatory Need: Harmonized PIC/S GMP. Its Overview and Comparison with WHO GMP. Pharmaceut Reg Affairs 4: 150 doi:10.4172/2167-7689.1000150

Copyright: $\odot 2015$ Kothari $\mathrm{C}$, et al. This is an open-access article distributed under the terms of the Creative Commons Attribution License, which permits unrestricted use, distribution, and reproduction in any medium, provided the original author and source are credited. 


\begin{tabular}{|l|l|}
\hline PIC & PIC/S \\
\hline Convention & Scheme \\
\hline Between Countries & Between Authorities \\
\hline A formal treaty & Informal Arrangement \\
\hline Has legal status & Has no legal status \\
\hline Focus only on inspection & $\begin{array}{l}\text { Focus on inspection, training \& developing } \\
\text { guidelines }\end{array}$ \\
\hline Mutual Recognition of inspection & Exchange of information \\
\hline
\end{tabular}

Table 1: Comparison between PIC and PIC/S.

on good manufacturing Practice. There was the legal treaty between the 10 member countries initially, i.e., Austria, Denmark, Finland, Iceland, Liechtenstein, Norway, Portugal, Sweden, Switzerland and United Kingdom. Later on other countries Hungary, Ireland, Romania, Germany, Italy, Belgium, France and Australia became the member of the PIC as it was expanded subsequently [1-8].

The goals [1] of the PIC was:

- Mutual recognition of inspections

- Harmonization of GMP requirements

- Uniform inspection systems

- Training of inspectors

- Exchange of information

- Mutual confidence

In early 1990s, it was realized that as per EU law only European Commission was authorized to sign agreements with other countries. Thus expansion of PIC cannot be possible unless European Commission became a member results into incompatibility. If PIC was to survive and expand, a way had to be found to overcome this legal impasse while retaining the main functions of PIC Consequently PIC/S was established and both PIC and PIC/S operates parallel under the same logo and abbreviation. While the major difference between PIC and $\mathrm{PIC} / \mathrm{S}$ has been depicted in Table 1 [1].

PIC/S is an informal cooperative arrangement between regulatory authorities in the field of Good Manufacturing Practice of Medicinal products for human or veterinary use. PIC/S also provides a comparable GMP inspection as it is open to authorities. As the scheme is an arrangement between authorities, it is very flexible, dynamic and proactive. PIC/S provides Good Manufacturing Practice (GMP) inspection reports and GMP certificates to be exchanged; but unlike PIC there is no legal obligation that member authorities must accept such reports or certificates [1].

\section{The PIC/S goal is:}

To lead the international development, implementation and maintenance of harmonized GMP standards and quality systems of inspectorates in the field of medicinal products [1].

The main functions of PIC/S are:

- To provide a forum for the training of GMP inspectors.

- To facilitate the exchange of information between member authorities.

- To develop guidance documents on GMP.

- To promote uniform interpretation of GMP.

- To encourage international harmonization of GMP.

- To develop and promote Quality Systems for GMP Inspectorate.
- To ensure that all Members comply with PIC/S standards (assessment of new applicants and reassessment of older inspectorates).

- To provide a forum for networking and confidence building amongst inspectors $[1,7]$.

The success of the PIC Scheme is based on the common sharing of the unwritten concepts or principle like [5]:

- Technical expert's Organization: It is purely technical organization in GMP regulatory field without getting involved in any political or discrimination issues. It is a major think-tank where new ideas related to GMP are debated by experts.

- Based on consensus and mutual trust: Every member has the equal rights and obligations are the base of the consensus in the PIC/S. While without isolating any member PIC/S always found a way forward and never let any to feel alone against the vast majority. Voluntary co-operation and assessment of the members for equivalence before membership are the major concept to establish the mutual trust.

- Driven by members: The organization is driven by its member's, i.e., participated regulatory authorities and secretariat who contribute to either PIC/S events or PIC/S functioning.

- Cemented by strong professional and personal links: A forum established for the brain storming, discussion on new ideas and information sharing with help of networking, PIC/S informal character and the strong personal link between individual member and inspectorate is the strength of PIC/S.

To PIC/S growing membership, a new sub-committee structure [8] has been developed as shown in Figure1 in order to:

- Favour to the participating authorities for participation.

- Establish a more participative and efficient organization of $\mathrm{PIC/S}$, where each sub-committee will be responsible for its respective core areas and will take the lead in developing policies.

\section{Membership procedure and assessment}

A detailed assessment of the regulatory authority is carried out to determine the equivalence of necessary arrangements and competency required for inspection system that of the current members before involving the regulatory authority in PIC/S. For the existing members also reassessment is also carried out for equivalence on regular basis. As it ensure that both new applicant and older member have to fulfill the same requirements. The relation with the organization is reviewed on the basis of (i) non- discrimination and equal treatment and (ii) non-duplication with member authorities. An examination of the authority's inspection and licensing system, quality system, legislative requirement, inspector training etc. and to observe inspectors carrying out routine GMP inspection on visit done by PIC/S delegation are included in the assessment procedure as shown on Figure $2[1,5,8]$.

While Membership procedure is divide into two parts:

Pre-accession procedure [1,8]: A new time period offers a softer approach and adjustment period by this procedure to the new applicant who have notable difference or may not familiar to the PIC/S standard. The time period for this procedure is 3 to 6 years in which the assessment and gap analysis of the applicant authority to PIC/S is carried out as well as during this procedure auditor appointed by the committee might take visit to the site. If inspectorate come under the specified condition as below, than only pre-accession has to be done: 
- The PIC/S GMP Guide does not apply to inspectorate,

- Inspectorate has not regularly participated in PIC/S training activities,

- Inspectorate is unsure whether it meets PIC/S requirements,

- Inspectorate has not yet introduced a QS similar along the lines of the PIC/S recommendation (PI 002),

- Inspectorate has requested to go through the pre-accession procedure.

Accession procedure $[\mathbf{1 , 8}]$ : It is time consuming process which provide some time to the inspectorate for completing the application and provide all necessary translation of the supporting documents. During this time inspectorate may have to take necessary measures to meet the PIC/S requirement and allow sufficient time for national industry to comply with PIC/S GMP guide (Figure 3).

\section{PIC/S GMP guide}

To develop GMP guidance document or new amended annexes to $\mathrm{PIC} / \mathrm{S}$ GMP Guide for Medicinal product the PIC/S working group is formed at the end of the annual PIC/S seminar. PIC/S guide is divided into two parts: Parts-I covers GMP principles for the manufacture of medicinal product and Part-II covers the GMP for active substance used as the starting materials. While it also contains Annexes, which provide the details on the specific area of activity. PIC/S work closely and co-operatively with European Medicines Evaluation Agency (EMEA) and EU to minimize duplication of effort in development of GMP guidance Document and GMP Guide through its working group
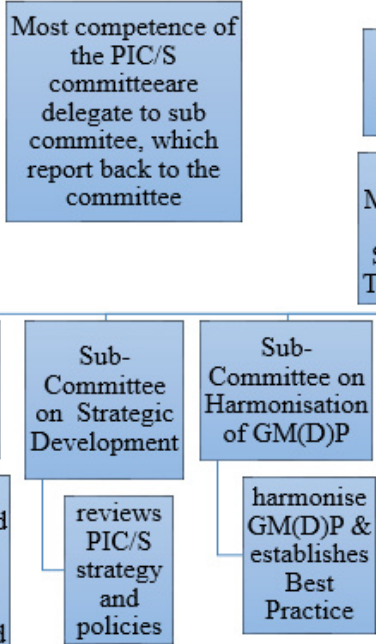

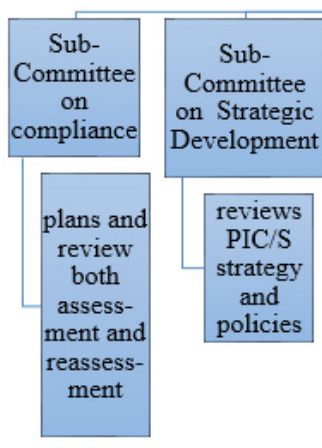

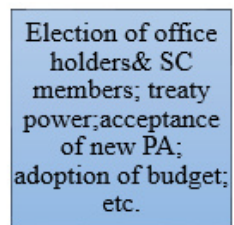

Plenary

Meeting:op

ate PIC

Scheme and

Take decision

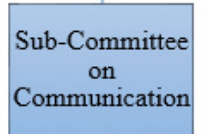

\begin{tabular}{|c|}
\hline Sub- \\
Committee \\
on Budget, \\
Risk \& \\
Audit \\
\hline
\end{tabular}

\begin{tabular}{|c|}
\hline $\begin{array}{c}\text { Sub- } \\
\text { Committe } \\
\text { e on } \\
\text { Expert } \\
\text { Circles }\end{array}$ \\
\hline $\begin{array}{c}\text { Review } \\
\text { activites } \\
\text { of } \\
\text { Expert } \\
\text { circles }\end{array}$ \\
\hline
\end{tabular}

\section{Define} communic -ation Strategy

\begin{tabular}{|c|c|}
\hline $\begin{array}{c}\text { Assesses } \\
\text { all risk, } \\
\text { reviews } \\
\text { audits; } \\
\text { prepares } \\
\text { Budgets }\end{array}$ & $\begin{array}{c}\text { Review } \\
\text { activites } \\
\text { of } \\
\text { Expert }\end{array}$ \\
& \\
circles
\end{tabular}

SubCommittee on Training

Figure 1: PIC/S new structure.

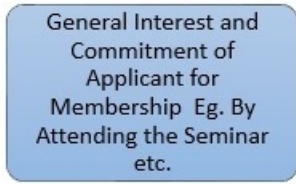

Commitment of

Applicant for

Attending the Seminar etc.
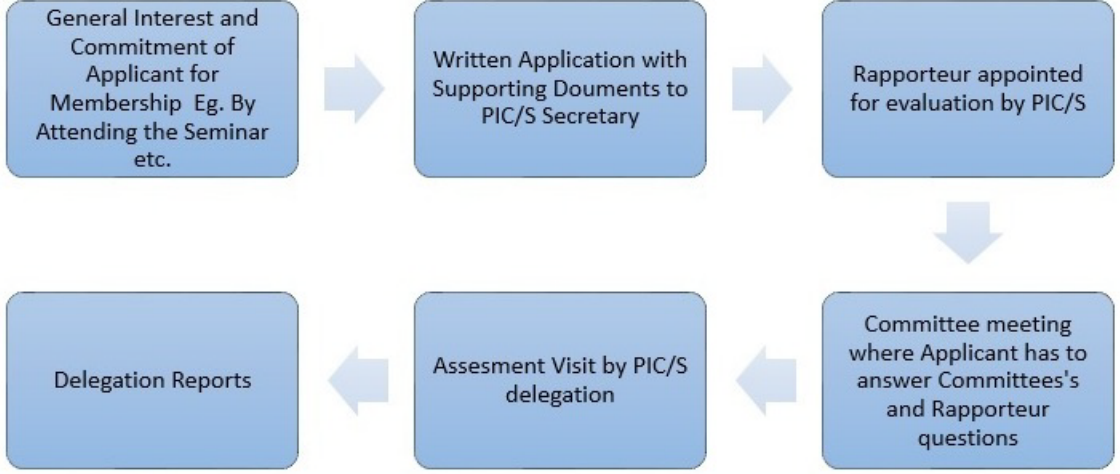

Figure 2: Steps of accession procedure. 
Citation: Kothari C, Patel R (2015) Regulatory Need: Harmonized PIC/S GMP, Its Overview and Comparison with WHO GMP. Pharmaceut Reg Affairs 4: 150. doi:10.4172/2167-7689.1000150

Page 4 of 5

\begin{tabular}{|c|c|c|}
\hline Topic & PIC/S GMP Guide & WHO GMP Guide: \\
\hline Quality Management & $\begin{array}{ll}- & \text { Chapter } 1 \text { in guide } \\
- & \text { It is divided into: } \\
\text { o } & \text { Quality assurance } \\
\text { o } & \text { Quality control } \\
\text { o } & \text { GMP for medicinal Product } \\
\text { o } & \text { Product Quality Review } \\
\text { o } & \text { Quality risk management }\end{array}$ & 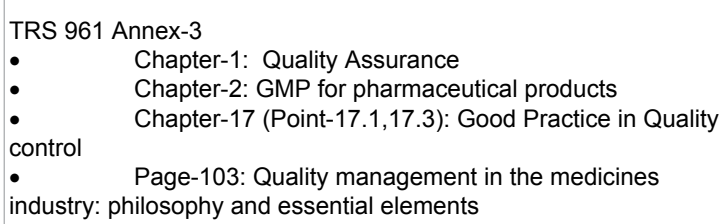 \\
\hline Personnel & $\begin{array}{ll}- & \text { Chapter-2 } \\
- & \text { It is divided into: } \\
\text { o } & \text { Key Personnel } \\
\text { o } & \text { Training } \\
\text { o } & \text { Personnel Hygiene }\end{array}$ & 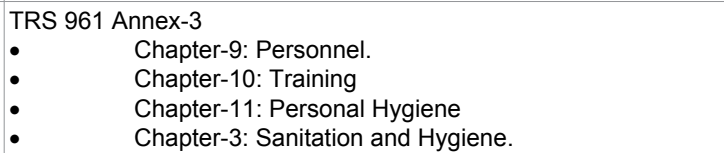 \\
\hline Premises and Equipment & $\begin{array}{ll}- & \text { Chapter-3 } \\
- & \text { It is divided into: } \\
\text { o } & \text { Premises } \\
\text { o } & \text { General } \\
\text { o } & \text { Production Area } \\
\text { o } & \text { Storage Areas } \\
\text { o } & \text { Quality Control Areas } \\
\text { o } & \text { Ancillary Areas } \\
- & \text { Equipment }\end{array}$ & $\begin{array}{l}\text { TRS 961, Annex } 3 \\
\text { Chapter 12: Premises } \\
\text { - } \\
\text { Chapter 13:Equipment } \\
\text { Chapter 9(Point 9.5): Personnel } \\
\text { in production }\end{array}$ \\
\hline Documentation & $\begin{array}{l}\text { Chapter }-4 \\
\text { It is divided into: } \\
\text { Required GMP Documentation } \\
\text { Generation and Control of Documentation } \\
\text { Good Documentation Practices } \\
\text { Retention of Documents } \\
\text { Specifications } \\
\text { Manufacturing Formula and Processing Instructions } \\
\text { Procedures and Records }\end{array}$ & $\begin{array}{l}\text { TRS 961, Annex } 3 \\
\text { - } \quad \text { Chapter-1 5: Documentation }\end{array}$ \\
\hline Production & $\begin{array}{ll}- & \text { Chapter-5 } \\
- & \text { It is divided into: } \\
\mathrm{o} & \text { Prevention of cross-contamination in production } \\
\mathrm{o} & \text { Validation } \\
\mathrm{o} & \text { Starting materials } \\
\mathrm{o} & \text { Processing operations - Intermediate and bulk products } \\
\mathrm{o} & \text { Packaging materials } \\
\mathrm{o} & \text { Packaging operations } \\
\mathrm{o} & \text { Finished products } \\
\mathrm{o} & \text { Rejected, recovered and returned materials }\end{array}$ & $\begin{array}{l}\text { TRS 961, Annex } 3 \\
\text { - } \\
\text { Chapter 14: Materials } \\
\text { - } \\
\text { Chapter 16: Good practices in production } \\
\text { Chapter 3: Sanitation and hygiene } \\
\text { Chapter 15 (Point 15.10): Documentation } \\
\text { Chapter 4 (Point 4.4, 4.8): Qualification and validation }\end{array}$ \\
\hline Quality Control & $\begin{array}{ll}- & \text { Chapter-6 } \\
- & \text { It is divided into: } \\
\text { o } & \text { Good Quality Control Laboratory Practice } \\
\text { o } & \text { Documentation } \\
\text { o } & \text { Sampling } \\
\text { o } & \text { Testing } \\
\text { o } & \text { On-going Stability Program }\end{array}$ & 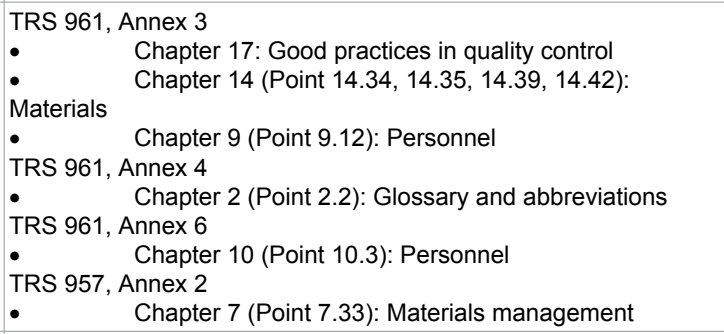 \\
\hline $\begin{array}{l}\text { Contract Manufacture and } \\
\text { Analysis }\end{array}$ & $\begin{array}{ll}- & \text { Chapter-7 } \\
- & \text { It includes details of: } \\
\text { o } & \text { Contract Giver } \\
\mathrm{o} & \text { Contract Acceptor } \\
\mathrm{o} & \text { Contract } \\
\end{array}$ & $\begin{array}{l}\text { TRS 961, Annex } 3 \\
\text { - } \quad \text { Chapter 7: Contract production and analysis }\end{array}$ \\
\hline $\begin{array}{l}\text { Complaint and Product } \\
\text { Recall }\end{array}$ & $\begin{array}{ll}- & \text { Chapter-8 } \\
- & \text { It includes details of: } \\
\text { o } & \text { Complaints } \\
\text { o } & \text { Recalls }\end{array}$ & $\begin{array}{l}\text { TRS 961, Annex } \\
\text { - } \quad \text { Chapter 5: Complaints } \\
\text { Chapter 6: Product recalls }\end{array}$ \\
\hline
\end{tabular}

Table 2: Comparison of PIC/S GMP and WHO GMP.

of GMP Inspectors. This co-operative arrangement, allows the EU to adopt the document developed by the PIC/S; likewise PIC/S can use the documents developed by the EU [2,7]. The PIC/S GMP Guide for Medicinal Products is almost identical to the EC GMP Guide; the main differences [2] are:

- The PIC/S GMP Guide uses the term 'authorized person' (rather than the term 'Qualified Person' in the EC GMP Guide).

- References to EU Directives have been removed from the PIC/S
GMP Guide.

The PIC/S GMP guide is derived from the WHO GMP guide and developed in order to comply with the stringent manufacturing and health requirements in the member countries. WHO GMP has detailed guidelines compared to the PIC/S GMP $[3,6]$ shown in Table 2.

Benefit of PIC/S Membership

The benefits [1,7] of PIC/S membership for regulatory authorities are fairly obvious, and include the following: 
Training of inspectors through participation in PIC/S Seminars and expert circles as well as in the PIC/S Joint Visits Program.

- Networking often simplifies contacts and exchange of GMP related information of various regulatory.

- More effective sharing GMP inspection result with help of inspection.

- Promotion of the harmonization of GMP inspections.

- Forces improvements in the inspection systems and procedures of authorities seeking to join PIC/S, through the PIC/S assessment process.

- Provides information sharing and experience amongst inspection.

The industry might be benefited as their regulatory authority is having PIC/S membership. These benefits $[1,7]$ may include the following:

- Reduces inspection duplication and its cost.

- Export facilitation.

- Enhanced market access.

The International Medicinal Inspectorates Database

PIC/S has developed a non-profit International Medicinal Inspectorates Database (IMID) which include information on the carried out or to be carried out GMP inspection reports by membered authorities as their list has been provided by PIC/S on website. Membered regulatory authority use the database to access information provided on GMP inspection of foreign site for approval process while they are committed to use the database through their acceptance of the IMID statute. The IMID also constitutes a new option for the sharing of information on the GMP compliance status of manufacturing sites for finished medicinal products, active pharmaceutical ingredients (APIs) and investigational_medicinal products. It is cost efficient by allowing inspection reports to be shared among all members and reduce the number of inspections as well as duplication of inspection report [1,7].

\section{Reason for INDIA to join PIC/S}

India being accredited with almost 1,105 CEPs, more than 950 TGA approvals and 584 sites registered by the USFDA leaves no doubt to the benefits of Indian Pharma Sector by joining PIC/S [9] will be:

- Forced improvement in the India's GMP inspection system and procedure as well as Quality system requirements

- Indian FDA's GMP regulation will be globally accepted after $\mathrm{PIC} / \mathrm{S}$ accession

- Reduction in the duplication of inspections and inspection report

- It will help boost exports and strengthen India's credentials as amongst the best quality manufacturers of pharmaceuticals globally

- Helps to facilitate networking and confidence-building
- Helps to upgrade the inspections quality and quality assurance of inspectorates

- Helps to coordinate training of inspectors

- Helps to enhance global harmonization of GMP

\section{Conclusion}

WHO-GMP standards are more Stringent than PIC/S-GMP standards but PIC/S has its own benefits, e.g., it helps the membered authority by to trade the medicinal products in the other member countries by removing the barrier as they all will be following the same PIC/S GMP standards. PIC/S GMP also provide the platform to promote the uniformity in licensing decision as well as to ensure the high standards of quality assurance in the development, manufacture and control of medicinal products. The IMID will also strengthen the partnership among the IMID users by providing the information regarding the inspections of the every membered authority. If India decides to implement PIC/S standard, adequate time and financial support to pharma companies should be provided by the government at affordable cost. As SMEs are schedule M complaint, they need to upgrade themselves by upgrading their facilities and equipment to WHO-GMP and PIC/S-GMP requirements and also require training on Quality Management System, Quality Risk Management, Product Quality Review, Stability studies and Change control.

\section{References}

1. (2015) The Pharmaceutical Inspection Convention and Pharmaceutical Inspection Co-operation Scheme, PIC.

2. (2014) Guide to Good Manufacturing Practice for Medicinal ProductsIntroduction/lCH of Technical Requirements for Registration of Pharmaceuticals for Human use March, Geneva.

3. (2014) Guide to Good Manufacturing Practice for Medicinal Products (Part-I and Part-II) / ICH of Technical Requirements for Registration of Pharmaceuticals for Human use March, Geneva

4. (2014) Guide to Good Manufacturing Practice for Medicinal Products-Annexes/ $\mathrm{ICH}$ of Technical Requirements for Registration of Pharmaceuticals for Human use, Geneva.

5. (2005) Pharmaceutical Inspection Co-operation Scheme Blueprint/ ICH of Technical Requirements for Registration of Pharmaceuticals for Human use, Geneva.

6. (2015) World Hepatitis Summit harnesses global momentum towards elimination, WHO

7. Daniel Brunner (2004) Pharmaceutical Inspection Co-operation Scheme (PIC/S), The Quality Assurance Journal.

8. Carmelo Rosa (2014) Pharmaceutical Inspection Co-operation Scheme (PIC/S). Presented at Global Drug Development International Collaboration.

9. Sachin Jagdale (2015) PIC/S Getting A Clearer Picture, Express pharma. 